\title{
A study of heavy metal complexation in grape juice
}

Íñigo Salinas, Irene Esparza, Sara Gómez, Carolina Santamaría, and José M. Fernández*

Departamento de Química y Edafología. Universidad de Navarra. 31080 Pamplona. Spain

*e-mail: jmfdez@unav.es_ Fax: +34 948425649

\begin{abstract}
Differential Pulse Anodic Stripping Voltammetry, DPASV, has been used to monitor the initial stages of grape juice fermentation, focusing on $\mathrm{Zn}$ interactions with natural occurring ligands. Langmuir and Scatchard linearization methods have been employed. A 1:1 ratio has been found by either method; from Langmuir data analysis only one ligand population was found, while Scatchard approach gave rise to the detection of two ligand types. Both data analysis procedures led to the same total ligand concentration. When catechin was used as model ligand, a 1:1 ratio was found for $\mathrm{Zn}$ and also for $\mathrm{Cu}$.
\end{abstract}

KEY WORDS: heavy metals, complexation, grape juice, catechin, stripping voltammetry

\section{INTRODUCTION}

Grapes, musts and, to a lesser extent, wine contain trace amounts of heavy metals [1-2]. It is recognized that the extent of the toxic effects is not governed by its total concentration, instead it is regulated by the forms of the metals (whose identification and characterization is called speciation) that can efficiently interact with sites of biological ligands. Unless exposed to significant airbone pollution, grapes accumulate only small amounts of heavy metals by translocation from the roots or by direct contact from vineyard sprays. They are normally absorbed into the yeast cell membrane during fermentation. Increased concentrations in wine result from contamination during post-fermentation processing.

Historically, characterization of wines has been conducted using sensoring analysis. However, at present quality control and regulatory requirements are forcing wineries to perform more analysis for both major and minor components [3-4]. This necessity will be a powerful driving force towards more sophisticated instrumental methods in the industry.

The official methods for the determination of heavy metals in wine are based mainly on atomic absorption spectroscopy although several chromatographic studies have discussed ion complexations in wine samples [5]. However, there is a limited number of studies concerning the speciation of metals in wine and particularly in must, although wine quality depends on must composition and vinification technology [6]. In this respect, advanced voltammetry -predominantly in the differential pulse mode- has 
become one of the most significant and suitable methods for investigations of the level, fate and transfer of heavy metals.

Among the factors that affect wine quality, cationic content and the form in which the cations exist are fundamental since they are important in the fermentative process [7]. In must, some metals such as $\mathrm{Zn}, \mathrm{Cu}$ and $\mathrm{Fe}$, at low concentrations, are cofactors for vitamins and enzymes [1,8]. In trace amounts, $\mathrm{Cu}$ and $\mathrm{Zn}$ are important inorganic catalyst for metabolic activities of microorganisms [9].

The micronutrients $\mathrm{Fe}, \mathrm{Zn}, \mathrm{Mn}$ and $\mathrm{Cu}$ are needed in low quantities by yeast, but are also important since they take part in maintenance and function of biological processes. Some of them make up the prosthetic group of certain enzymes called metalloenzymes. The presence of metals in wine notably influences its organoleptic quality.

$\mathrm{Zn}$ is an oligoelement who plays a very important role in the metabolism of auxines, which are the hormones responsible for the growth of the plants. The absence of this metal can inhibit the fermentative process and provoke a decrease in size and a modification of distribution and colour of plant leaves [10] .

Copper is present in wine in trace amounts and acts as a catalyser in metabolic processes taking place in wine. More specifically, it catalyses the synthesis of the above mentioned auxines. A copper deficit in chlorophyll can induce its decomposition and decrease the yield of the vineyard [11].

The present work deals with the assessment of a voltammetric approach to discriminate the presence of both free and complexed metals in grape juice, must and wine, as the initial stage of a larger scope project in which the metal-polyphenol interaction may be thoroughly studied and its influence on wine color checked. For this basic study a grape juice was chosen, and $\mathrm{Zn}$ was selected as model heavy metal. The use of adequate algorithms has proved that $\mathrm{Zn}$ interacts with naturally occurring ligands and it allowed us to monitor the following variables:

a) Complexation capacity of the ligands from the grape juice.

b) Labile concentration of $\mathrm{Zn}$

c) Total concentration of $\mathrm{Zn}$

d) The affinity of the natural ligands for $\mathrm{Zn}$.

On the other hand a grape juice sample was allowed to undergo spontaneous fermentation of its own. Zn concentration has been evaluated along a 5-week period. The findings of this work have facilitated a most comprehensive study of natural occurring metals and polyphenols in must along a proper fermentation under real cellar conditions, that have been reported elsewhere [12]. 


\section{EXPERIMENTAL}

Materials. Vitis vinifera var. garnacha grape juice, supplied by the Station of Enology and Viticulture of Navarra, EVENA, was used throughout without any further conditioning.

All reagents were Suprapur grade (Merck). Nitric acid was further distilled in our laboratory under sub-boiling conditions.

Plastic material (polypropylene) was washed with deionized distilled water, soaked for $24 \mathrm{~h}$ in $10 \%$ nitric acid and, finally, rinsed several times with deionized distilled and ultrapure water.

\section{Apparatus}

Voltammetric measurements were performed with an Autolab PGSTAT12 system (Ecochemie. B.V., Utrecht, Netherlands) connected to a Metrohm (Herisau, Switzerland) 663 VA stand equipped with a static mercury drop electrode (SMDE) of the minimum size. A conventional three-electrode arrangement, consisting of a glassy carbon counter electrode, an $\mathrm{Ag}-\mathrm{AgCl}(3 \mathrm{M} \mathrm{KCl})$, reference electrode and Metrohm multimode mercury electrode was used.

Atomic Absorption Spectroscopy (AAS) measurements were done by means of a Perkin-Elmer (Beaconsfield, PQ, Canada) Atomic Absorption Spectrometer AAnalyst 800.

A high-pressure Milestone (Sorisole, BG, Italy) ETHOS PLUS Microwave Labstation equipped with a Milestone LabTerminal 800 Controler was used for sample digestions. Vessels were TFM Teflon® type.

\section{Procedures.}

Voltammetry. Differential Pulse scanning mode was used throughout to perform the Anodic Stripping Voltammetry measurements. The instrumental settings for Zn were as follows: deposition time $\left(\mathrm{t}_{\mathrm{d}}\right): 60 \mathrm{~s}$ under 3,000 rpm stirring; deposition potential $\left(\mathrm{E}_{\mathrm{d}}\right):-1.2 \mathrm{~V}$; equilibration time $\left(\mathrm{t}_{\mathrm{eq}}\right): 20 \mathrm{~s}$; initial potential $\left(\mathrm{E}_{\mathrm{i}}\right):-1.2 \mathrm{~V}$; final potential $\left(\mathrm{E}_{\mathrm{f}}\right):-0.8 \mathrm{~V}$; pulse amplitude: $50 \mathrm{mV}$; step potential: $4.95 \mathrm{mV}$.

The instrumental settings for $\mathrm{Cu}$ measurements were: deposition time $\left(\mathrm{t}_{\mathrm{d}}\right): 60 \mathrm{~s}$ under 3,000 rpm stirring; deposition potential $\left(\mathrm{E}_{\mathrm{d}}\right)$ : $-0.6 \mathrm{~V}$; equilibration time $\left(\mathrm{t}_{\mathrm{eq}}\right): 20 \mathrm{~s}$; initial potential $\left(\mathrm{E}_{\mathrm{i}}\right)$ : $-0.6 \mathrm{~V}$; final potential $\left(\mathrm{E}_{\mathrm{f}}\right): 0.15 \mathrm{~V}$; pulse amplitude: $50 \mathrm{mV}$; scan rate: $25 \mathrm{mV} / \mathrm{s}$.

Samples were deaerated for $300 \mathrm{~s}$ at the beginning of each set of experiments; the cell was further deaerated for $10 \mathrm{~s}$ after every spike of standard. Prior to electrochemical measurements, a conditioning time ( $\left.t_{\text {cond }}\right)$ of 30 min was allowed so that $\mathrm{Zn}$ might equilibrate with present ligands. Quantitation was carried out using the standard addition method (from three to eighteen additions per sample). An exact volume of grape juice was diluted to $25.00 \mathrm{~mL}$ with ultrapure water and transferred into the electrochemical cell.

Atomic absorption spectrometry. The method of external calibration against aqueous standards (in s.b. $1 \% \mathrm{HNO}_{3}$ ) was applied to the samples. The element was measured under the optimum operating conditions with an air-acetylene flame.

Microwave oven. A $0.60 \mathrm{~mL}$ aliquot of grape juice was added into TFM Teflon vessels together with $8.00 \mathrm{~mL}$ of concentrated $\mathrm{HNO}_{3}$ (the acid digestion agent); the reactor was then closed and heated. The vessels were cooled in an ice bath before being opened. The contents of each vessel were quantitatively transferred into a $10.00 \mathrm{~mL}$ 
volumetric flask and made up to volume with water. A blank was treated in the same way. The heating profile was as follows: samples were heated from room temperature up to $90^{\circ} \mathrm{C}$ following a ramp that takes $8.5 \mathrm{~min}$ to be completed. This temperature was kept constant for 6 more minutes. Afterwards, a new ramp taking 8 min was applied to rise the temperature up to $110^{\circ} \mathrm{C}$, and finally a third ramp was employed for 9 min to achieve a plateau of $170^{\circ} \mathrm{C}$ that was maintained for 8 additional minutes. A $20 \mathrm{~min}$ ventilation step completed the whole sequence.

Wet digestion. $5.0 \mathrm{~mL}$ must were thoroughly mixed with $2.0 \mathrm{~mL}(1: 1)$ nitric acid in open vessels placed on a sand bath for 2 hours at $50^{\circ} \mathrm{C}$.

\section{RESULTS AND DISCUSSION}

Optimization of the experimental parameters. Preliminary studies were carried out involving $\mathrm{Zn}$ analysis. It is a well known fact that some metal complexes need a certain time to be formed. This time is referred to as conditioning time $\left(t_{\text {cond }}\right)$. Thus, when $\mathrm{Zn}$ is spiked unto a natural must sample a kinetics-depending response could be expected. Different conditioning times of up to $90 \mathrm{~min}$ were allowed to elapse between the spiking of the metal and the measurements in a 25 -fold diluted grape juice, to see how long does it take for the $\mathrm{Zn}$ to equilibrate with naturally occurring ligands. From the experimental measurements it was clearly seen that $\mathrm{Zn}$ requires a minimum of $30 \mathrm{~min}$ period to fully equilibrate with the ligands of the grape juice. Another set of experiments were carried out in buffered grape juice solutions $(\mathrm{pH} 4.3$ acetic-acetate, with $10 \%$ ethanol) where the alcohol was added in order to provide experimental conditions close to those existing in wine as final product. Buffered and unbuffered solutions behaved in exactly the same way. This proved that acetic acid had not complexation capacity with respect to $\mathrm{Zn}$, and accordingly this buffer could be used when necessary.

Titration of must samples. Once the optimum conditions have been established for the voltammetric measurements, titration procedures were applied in order to follow up the complexometric behavior of $\mathrm{Zn}$ by means of DPASV. Increasing amounts of $\mathrm{Zn}$ were added to the grape juice, and after the conditioning and preconcentration steps on the mercury, the anodic signal was recorded. The preconcentration step could be written as:

$$
\begin{aligned}
& \mathrm{Zn}^{2+}+\mathrm{Hg} \leftrightarrows \mathrm{Zn}(\mathrm{Hg})^{0} \\
& \mathrm{ZnL}+\mathrm{Hg} \leftrightarrows \mathrm{Zn}(\mathrm{Hg})^{0}+\mathrm{L}^{2-}
\end{aligned}
$$

depending on whether the metal is free in solution or complexed by natural ligands. It is only logical that peak intensities will be higher, for a given concentration of $\mathrm{Zn}$, when ligands do not have complexing sites available for $\mathrm{Zn}$, than when the complexing capacity is not reached. When plotting $\mathrm{i}_{\mathrm{p}}$ vs. added $\mathrm{Zn}$ concentration, two distinct linear portions will appear as in Figure 1.

The lower one corresponds to that situation in which all $\mathrm{Zn}$ is complexed by the ligands, and consequently it is amalgamated on the mercury from a complexed state. The second one, steeper, corresponds to those situations in which the complexing sites are saturated, and added $\mathrm{Zn}$ remains free in solution from where it is easier to preconcentrate onto the electrode surface. 
After each addition, the equilibrium labile metal concentration, [Zn'], present in solution was determined. $\mathrm{Zn}^{\prime}$ is the metal freed by the ligand in favor of the mercury under the time scale of the technique. In solution, [ $\left.\mathrm{Zn}^{\prime}\right]$ is related to the peak current, $\mathrm{i}_{\mathrm{p}}$, measured at the hanging mercury drop by:

$$
\left[\mathrm{Zn}^{\prime}\right]=\frac{\mathrm{i}_{\mathrm{p}}}{\mathrm{s}}
$$

where $\mathrm{s}$ is the sensitivity, that is to say the slope of the steeper line. The $\mathrm{Zn}$ remaining complexed in solution, $\mathrm{ZnL}$, is readily related to the total $\mathrm{Zn}$ concentration in solution, $\mathrm{Zn}_{\mathrm{T}}$, by:

$$
[\mathrm{ZnL}]=\left[\mathrm{Zn}_{\mathrm{T}}\right]-\left[\mathrm{Zn}^{\prime}\right]
$$

As increasing amounts of standard $\mathrm{Zn}$ are added, the anodic signal increases as a consequence on increased complex being formed. A marked change in the shape of the titration curve occurs when the metal concentration is equivalent to that of the ligand. Beyond this point, the metal complexation capacity of the ligand is saturated, and the slope of the upper portion of the titration curve is identical to the slope of the titration curve obtained when no ligand is present.

Both, final dilution of the grape juice sample in the electrochemical cell and the standard concentration of $\mathrm{Zn}$ to be used were optimized to obtain a well defined titration curve, i.e., with two distinct portions depicting the unsaturated and saturated ligand situation. The titration curves obtained for different dilutions are shown in Figure 1. The overall shape of the titration curve indicates the extent and nature of complexation in the sample. Extrapolation of the upper linear portion of the titration curve down to the abscissa, gives a crude measure of the ligand concentration. It could be seen in Figure 1 that complexation capacity decreases with increasing dilution of the sample. On the contrary, a concentrated sample lead to the destabilization of the mercury drop due to the high density of the solution. As a compromise, a 25-fold dilution was established. 

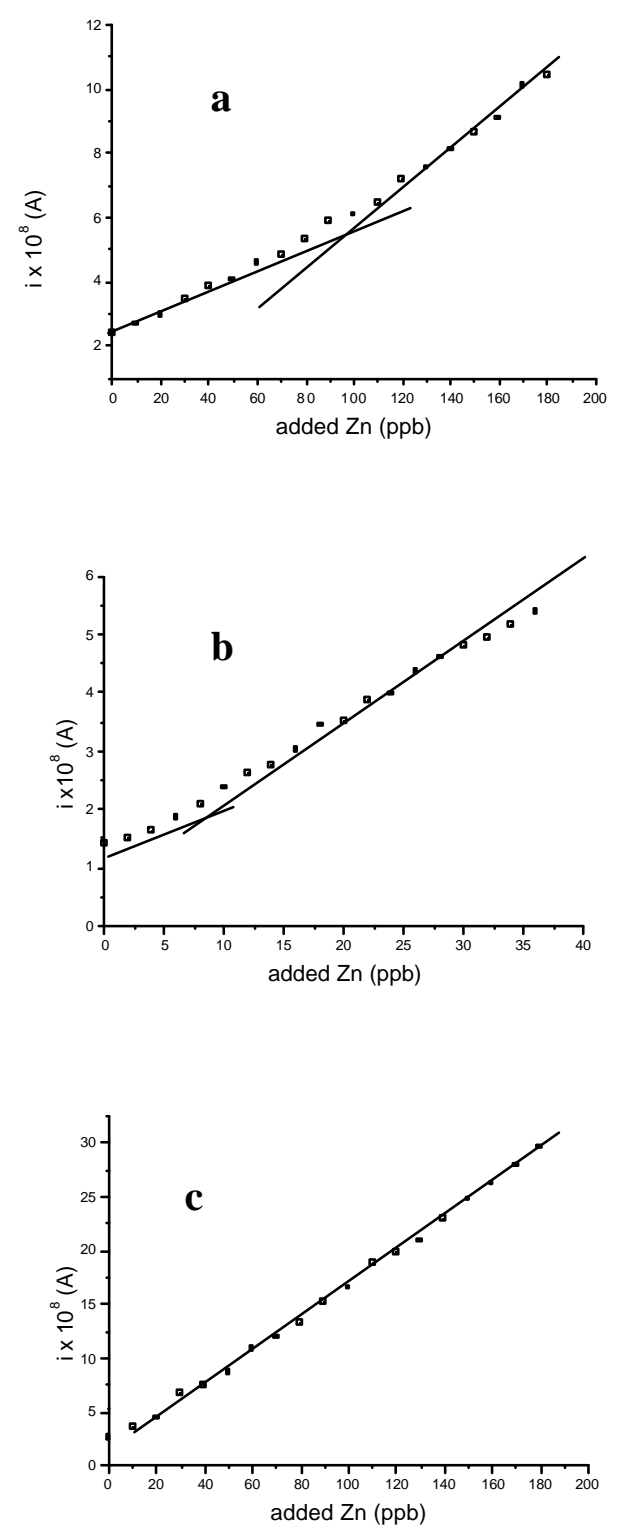

Figure 1. Effect of dilution on titration curves of aqueous unbuffered solutions of grape juice.

a) Dilution 1:5; b) Dilution 1:25; c) Dilution 1:50

Evolution of $\mathrm{Zn}$ during the fermentative process. It is well known that the fermentative process starts at room temperature. The grape sugar is converted by yeast enzymes into alcohol and carbon dioxide, and it lasts for three to seven days, approximately. The cationic content and the form in which the cations exist in the grape juice are important since they play a relevant role in the fermentative process, and subsequently exert a marked influence on the organoleptic quality of the wine.

In order to study the evolution of the chemical forms of $\mathrm{Zn}$ along the fermentation, the grape juice was allowed to ferment naturally under laboratory conditions and it was periodically analyzed by DPASV for up to five weeks. 
The following facts were observed:

- As fermentation took place, carbonic gas evolved giving rise to increasing bubbling of the solution as time passed by.

- Sedimentation started to happen and sediment appeared visibly in the bottom of the container. After a seven-day period, it ceased to grow. By that time, bubbling had come to a complete stop, marking the end of the fermentation with all the sugar converted into alcohol.

- Density measurements confirmed that sugar content had collapsed after the seventh day.

- The labile $\mathrm{Zn}$ concentration steeply decreased from the start, reaching a minimum value after a four-day period of the fermentation process. Afterwards, it reached a concentration plateau around $70 \mu \mathrm{g} / \mathrm{L}$ (see Figure 2).

Zn could be mechanically carried away as a result of the flocculation and precipitation processes. This hypothesis was proved by dissolving the sediment obtained after a period of 5 weeks with nitric acid (1:1), and measuring Zn by DPASV. A good portion of $\mathrm{Zn}$ was found to be in the sediment, while a value of ca. $70 \mu \mathrm{g} / \mathrm{L}$ remained in solution as shown in Figure 2.

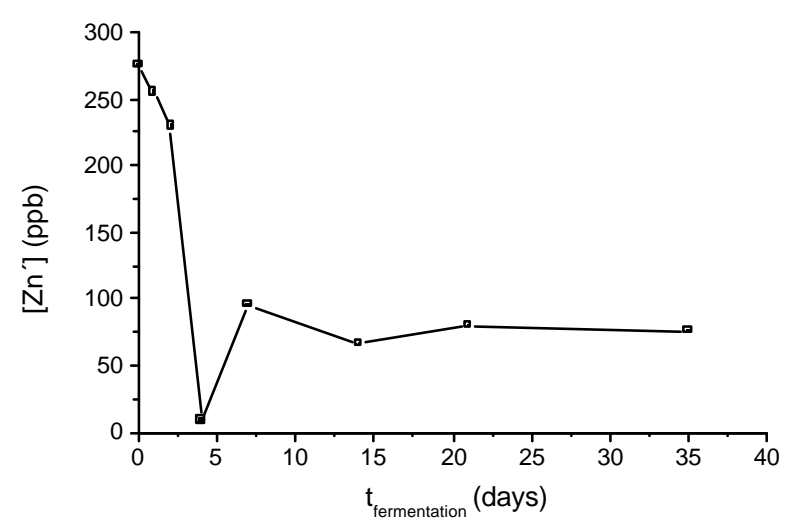

Figure 2. Evolution on labile $\mathrm{Zn}$ ([Zn']) with fermentation time. Aqueous 1:25 unbuffered solution of grape juice.

Total zinc determinations. Calculation of the complexation parameters requires an independent measurement of total metal concentration, $\left[\mathrm{Zn}_{\mathrm{T}}\right]$, to be made. In order to find the best conditions to release the bound zinc, the must samples were subjected to two different digestion procedures:

Wet digestion. Assayed nitric acid concentrations were varied from $10 \%$ to concentrated; 1:1 nitric acid was found to be most suitable for this purpose since it yielded most reproducible and agreeable peak intensities by both DPASV and AAS. The sample looses its color when digested with nitric acid, what would indicate a successful destruction of the organic matter. Nevertheless, the shape of the titration curve shows that, even when concentrated nitric acid was used, the complexing capacity of the sample is not completely removed. Besides, the values calculated for $\mathrm{Zn}_{\mathrm{T}}$ were of ca. $420 \mu \mathrm{g} / \mathrm{L}$, lower than those obtained after a microwave digestion (see below). 
Microwave oven digestion. As an alternative to the previous procedure, Microwave oven digestion technique has become popular due to the reduced reagent amount and time required for sample treatment, and flexible temperature programming. Sample attack was done by means of a large volume of concentrated $\mathrm{HNO}_{3}(8.0 \mathrm{~mL})$ poured on a $0.6 \mathrm{~mL}$ sample. Digested samples appeared as greenish and fully transparent solutions. Due to the very low resulting $\mathrm{pH}, \mathrm{Zn}$ could not be electrochemically measured, and we turned to AAS instead. This methodology was the most satisfactory of the two, and was taken as the method of our choice for the remaining studies. The found value of $750 \mu \mathrm{g} / \mathrm{L}$ was taken as true for $\left[\mathrm{Zn}_{\mathrm{T}}\right]$ hereafter.

Ligand concentrations, stability constants and zinc speciation. From the above experimental findings we picked up three instances as most representative, that is to say: fresh grape juice (0-day fermentation), 4-day fermentation, and 5-week fermentation. The titration curves are shown in Figure 3. Figure $3 b$ corresponds to that situation with the minimum found concentration of labile $\mathrm{Zn}$ (cfr Figure 2). In such a case the kinetics of complexation by the present ligands is faster and the curve shows a very smooth and typical shape. In cases a) and c) labile $\mathrm{Zn}$ is higher, especially in the first one, giving rise to a slower equilibration kinetics (even after 30 min equilibration time) what produces a graph with an unstable intermediate part. It can also be seen a distinct pattern for the slopes of the second linear portions. When fermentation has not taken place (Fig. 3a), the slope is highest, whereas that value decreases notably for the 4-day and remains constant throughout all the process. This behavior means that equal amounts of added zinc yield a higher peak intensity in the fresh grape juice than in the fermented one. It means that the preconcentration of the metal is easier, that is to say is more readily released by the ligands present in the grape juice. However, when fermentation proceeds a more stable complex(es) seem to be generated, since the slope diminishes showing that $\mathrm{Zn}$ is more strongly bounded by the new ligand. 

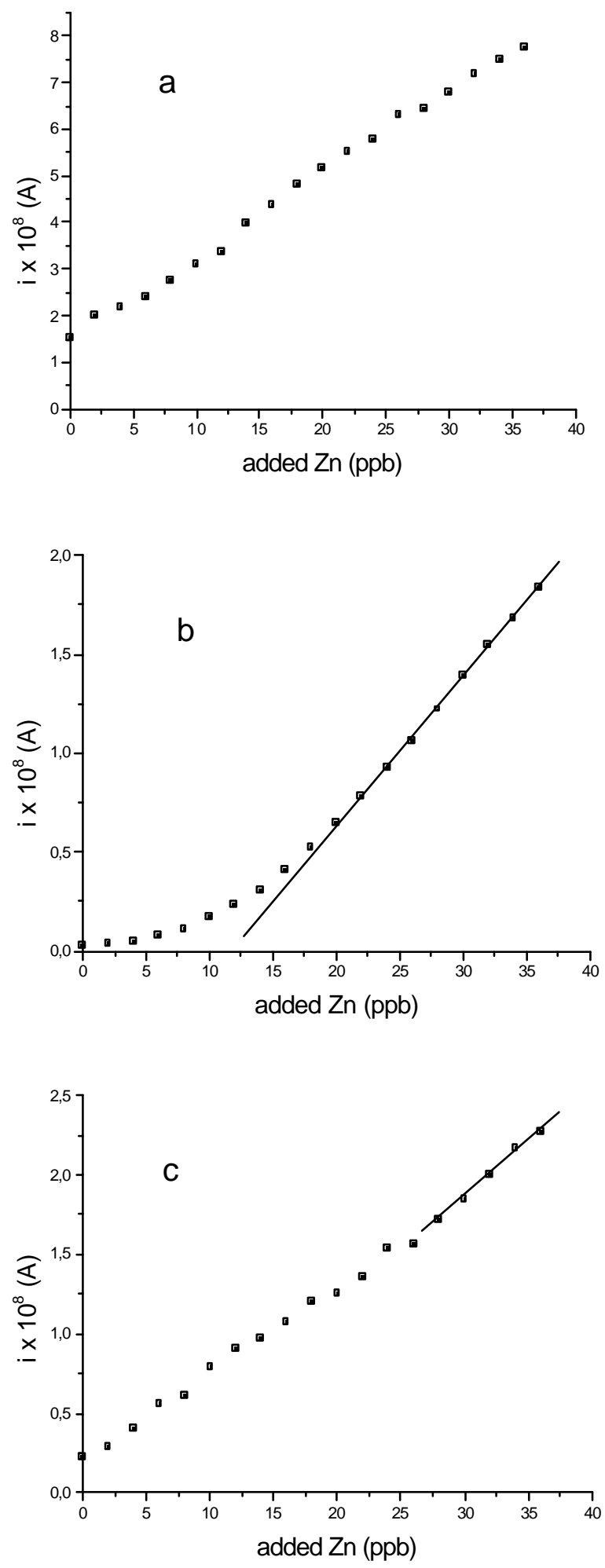

Figure 3. Aqueous unbuffered 1:25 grape juice titrated with $\mathrm{Zn}$ at different fermentation stages: a) 0-day (fresh grape juice); b) after 4-day fermentation; c) 35-day (fully fermented sample). 
Ligand concentrations and stability constants of $\mathrm{Zn}$ complexes can be calculated aided by Langmuir and Scatchard linearization methods [13]. Both treatments can be derived simply by considering the metal ligand equilibrium in solution. The conditional stability constant, $\mathrm{K}^{\prime}$, relates to the following equilibrium: $\mathrm{K}^{\prime}=\frac{[\mathrm{ML}]}{[\mathrm{M}] \cdot[\mathrm{L}]}$, where the total ligand concentration, $\left[\mathrm{L}_{T}\right]$, is given by $\left.\mathrm{L}_{T}\right]=[\mathrm{ML}]+[\mathrm{L}]$. In these definitions, $[\mathrm{ML}]$ is the concentration of metal/ligand complexed, $[\mathrm{M}]$ is the free metal concentration, and $[\mathrm{L}]$ is the free ligand concentration. Substitution and rearrangement of these two equations gives:

$$
\frac{[M L]}{\left[M^{\prime}\right]}=K^{\prime}\left[L_{T}\right]-K^{\prime}[M L]
$$

Equation (3) is commonly known as the Scatchard equation. A plot of titration data in the form $[\mathrm{ML}] /[\mathrm{M}]$ vs $[\mathrm{ML}]$ will give a straight line of gradient $-\mathrm{K}^{\prime}$ and $\mathrm{y}$-axis intercept $\mathrm{K}^{\prime}\left[\mathrm{L}_{T}\right]$. The Langmuir linearization, also called Ruzic/van den Berg linearization method [14-16] is defined as:

$$
\frac{\left[\mathrm{M}^{\prime}\right]}{[\mathrm{ML}]}=\frac{[\mathrm{M}]}{\left[\mathrm{L}_{\mathrm{T}}\right]}+\frac{1}{\mathrm{~K}^{\prime}\left[\mathrm{L}_{\mathrm{T}}\right]}
$$

The ratio of $\left[\mathrm{M}^{\prime}\right] /[\mathrm{ML}]$ is plotted against $\left[\mathrm{M}^{\prime}\right]$, a linear relationship is usually obtained with a slope equal to $\frac{1}{\left[\mathrm{~L}_{T}\right]}$ and with the intercept yielding $\frac{1}{\mathrm{~K}^{\prime}\left[\mathrm{L}_{\mathrm{T}}\right]}$. It has been stated that this graphical solution is superior to the Scatchard plot, thought few direct comparisons of the two treatments have been presented.

The use of either treatment assumes that metal complexation in the sample can be adequately represented by a single ligand forming 1:1 stoichiometry complexes. Curvature in either plot is taken as an indication of the presence of two or more ligands of different stability constants.

Results obtained for a fresh grape juice by Langmuir linearization allowed the quantitation of only one type of ligand (Figure 4a), whereas the Scatchard data treatment clearly shows two populations of data that can be adjusted to two linear portions (Figure $4 \mathrm{~b}$ ). The $\mathrm{x}$ axis intercepts of these straight lines provide the abundance of each ligand present. Assuming that there were two different kinds of ligands, values of total concentration of ligand, $\left[\mathrm{L}_{\mathrm{T}}\right]$, and of the conditional constants, $\mathrm{K}^{\prime}$, were determined as it was explained before. It should be emphasized that the aim of this work is not to obtain the exact value of the parameters, but only to prove the ability of the technique to follow-up all the fermentation process and to detect the changes in the complexation state of the zinc along it. The $\log \mathrm{K}^{\prime}$ obtained by both linearization methods was almost the same (see Table 1) and the concentration of ligands $\left(\left[\mathrm{L}_{1}\right]+\right.$ $\left[\mathrm{L}_{2}\right]$ ) from the Scatchard's method is similar to $\left[\mathrm{L}_{\mathrm{T}}\right]$ from Langmuir. As regard as $\mathrm{Zn}$ complexation, it was observed that fermentation is a competitive process with complexation, since it acts withdrawing $\mathrm{Zn}$ from the solution. 

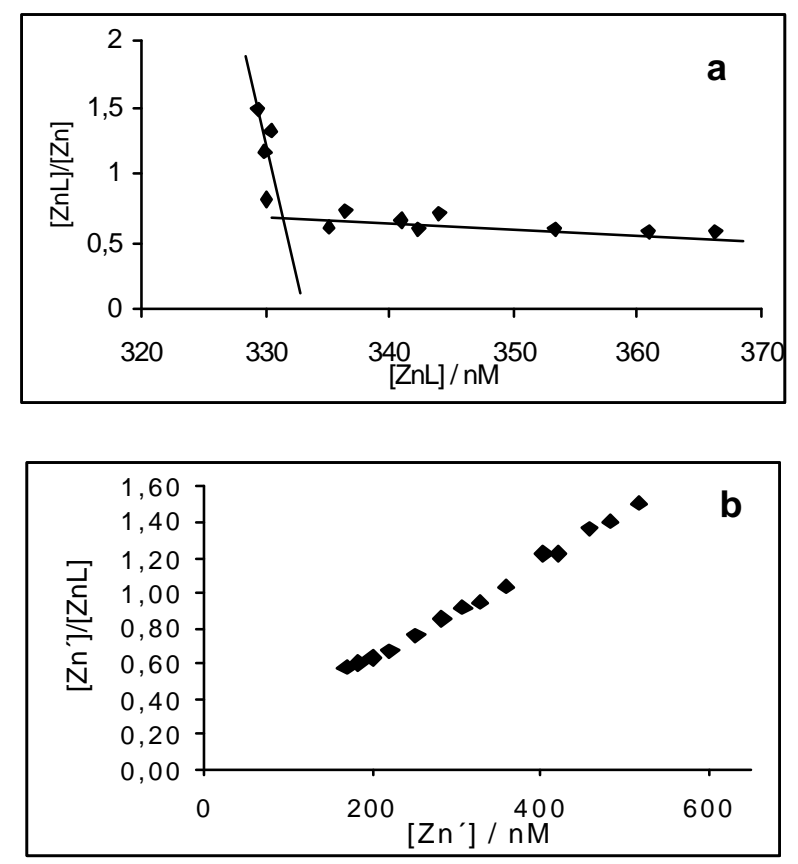

Figure 4. Scatchard (a) and Langmuir (b) plot of a 1:25 diluted aqueous unbuffered grape juice sample spiked with increasing concentrations of $\mathrm{Zn}$

When 4- and 35-day fermented juice was subjected to the same procedure, similar results were obtained by applying both linearization methodologies as shown in Table 1. As it can be seen, ligand population seem to have increased in the fermented samples, what is not strange if we take into account the overall chemical process involving disappearing and appearing of new chemical species.

\begin{tabular}{|c|c|c|c|c|c|c|}
\hline \multirow{2}{*}{$\begin{array}{c}t_{\text {fermentation }} \\
\text { (days) }\end{array}$} & \multicolumn{2}{|c|}{ Langmuir } & \multicolumn{4}{|c|}{ Scatchard } \\
\hline & {$[\mathbf{L}]_{\mathrm{T}} \quad(\mathbf{n M})$} & $\log K_{\mathrm{ZnL}}^{\prime}$ & {$[\mathbf{L}]_{1} \quad(\mathrm{nM})$} & $\log K_{\mathrm{ZnL} 1}^{\prime}$ & {$[\mathbf{L}]_{2} \quad(\mathrm{nM})$} & $\log K_{\mathrm{ZnL2}}^{\prime}$ \\
\hline 0 & 526 & 10.4 & 333 & 9.5 & 200 & 10.3 \\
\hline 4 & 769 & 9.3 & 683 & 8.8 & 122 & 9.5 \\
\hline 35 & 714 & 10.4 & 623 & 9.7 & 119 & 10.7 \\
\hline
\end{tabular}

Table 1. Data analysis according to Langmuir and Scatchard obtained for a grape juice when fresh ( 0 day), in fermentation process (4 day), and fermented (35 day). Unbuffered aqueous solutions; dilution 1:25 
Stoichiometry of complexes with individual model ligands. Up to now, we have found that $\mathrm{Zn}$ associates with either one or two populations of natural occurring ligands in grape juice. Since anthocyanins are common in wine and musts, and they are responsible for color forming, a further step was taken in order to check whether $\mathrm{Zn}$ would associate with them. It is well known that malvidin-3-glucoside and cyanidin-3glucoside are major anthocyanins present in grape juice, must and wine. Due to its structural similarity and to its availability, catechin was chosen as a ligand model to study in combination with both $\mathrm{Zn}$ and $\mathrm{Cu}$, since both metals could be directly involved in complex formation with influence in the final red wine color. Aqueous buffered solutions $(\mathrm{pH} \mathrm{4})$ of ligand were separately treated with increasing amounts of either $\mathrm{Zn}$ or $\mathrm{Cu}$, and the anodic stripping responses of the metals were recorded. Fig 5 shows the response for both $\mathrm{Cu}$ (a) and $\mathrm{Zn}$ (b). Again two linear portions were attained for both metals, $\mathrm{Cu}$ showing the larger difference in the values of the slopes. In both instances, the ratio of concentrations for which the slope of the anodic signal undergoes a change indicate that a 1:1 complex is formed. This finding will be given further attention, and theoretical studies will be undertaken to try and find the possible linking position on the structure of the organic molecule. Reports in the literature support a 1:3 ratio [17] but all of them have been done at $\mathrm{pH}$ ca. 8 or higher. It our case, a $\mathrm{pH}$ close to 4 has always been chosen to guarantee the natural conditions in musts and wines.
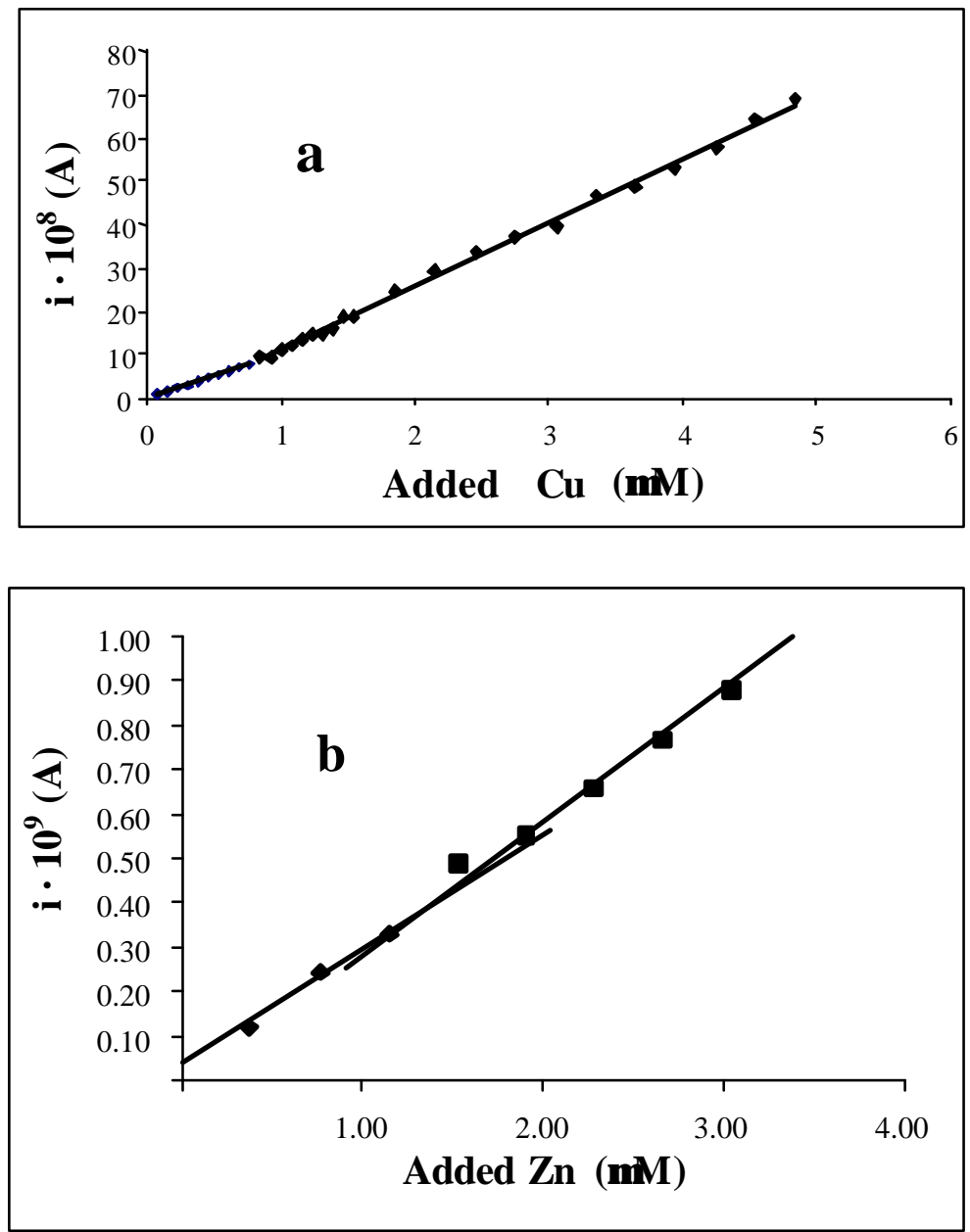

Figure 5.: Titration curves with $\mathrm{Cu}$ and $\mathrm{Zn}$ of buffered $\mathrm{pH} 4.0$ catechin solutions. a) 0.8 $\mu \mathrm{M}$ catechin; b) $1,4 \mu \mathrm{M}$ catechin 


\section{CONCLUSIONS}

It has been shown that voltammetric techniques are suitable to trace the fate and evolution of $\mathrm{Zn}$ in a grape juice that has been allowed up to a 5-week fermentative period of its own. Two ligand populations seem to exert the maximum complexing capacity on $\mathrm{Zn}$. Based on the knowledge of the presence of anthocyanins and related polyphenols in musts and wines, a model compound was assayed and its complexing capacity on both $\mathrm{Zn}$ and $\mathrm{Cu}$ has been proved. These findings have enabled us to take a further step to follow-up in a similar way several heavy metals in must samples throughout a whole vinification process for a 1-year period as published elsewhere [12].

\section{REFERENCES}

[1] C. Fernández Pereira, Z. Lebensm. Unters. Forsch. 1988, 186, 295.

[2] H.F. Linskens and J.F. Jackson, Wine Analysis, Springer-Verlag, 1988.

[3] L.Usseglio-Tomasset, Química Enológica, Mundi Prensa, 1998.

[4] E. Peynaud, Enología Práctica, Mundi Prensa, 2000.

[5] J. Ribéreau-Gayon, E. Peynaud, P. Sudraud, P. Ribéreau-Gayon, Tratado de Enología: Ciencias y Técnicas del Vino, Vol.I, Hemisferio Sur, 1980.

[6] J. Garrido, B. Ayestarán, P. Fraile, C. Ancín, J. Agric. Food Chem., 1997, 45, 2843.

[7] J. Ribéreau-Gayon, E. Peynaud, P. Ribéreau-Gayon, P. Sudraud, Tratado de Enología: Ciencias y Técnicas del Vino, Vol.III, Hemisferio Sur, 1992.

[8] H. Eschnauer, Am. J. Enol. Vitic., 1982, 33, 226.

[9] I. Karadjova, B. Izgi, S. Gucer, Spectrochim. Acta, Part B, 2002, 57, 581.

[10] P. Ribéreau-Gayon, Y. Glories, M. Manjean, D. Dubourdieu, The Handbook of Enology: Microbiology of Wine, Volume 2, The Chemistry of Wine Stabilisation and Treatments, John Wiley and Sons, 2000. [11] P. Hendrix, R. van Cauwenbergh, H. Robberecht, H. Deelstra, Z. Lebensm. Unters Forsch. A, 1998, 206, 222.

[11] J.R. Lissarrague, private communication.

[12] I. Esparza, I. Salinas, I. Caballero, C. Santamaría, I. Calvo, J.M. García-Mina, J.M. Fernández Anal. Chim. Acta (in press)

[13] G. Scatchard, Ann. N.Y. Acad. Sci., 1949, 51, 660.

[14] C.M.G. van den Berg, J.R. Kramer, Anal. Chim. Acta, 1979, 106, 113.

[15] I. Ruzic, Anal. Chim. Acta, 1982, 140, 99.

[16] C.M.G. van den Berg, H. Zi Qiang, J. Electroanal. Chem., 1984, 177, 269.

[17] G. Le Nest, O. Caille, M. Woudstra, S. Roche, B. Burlat, V. Belle, B. Guigliarelli, D. Lexa, Inorg. Chim. Acta, 2004, 357, 2027.

\section{ACKNOWLEDGEMENTS}

This work has been fully funded by the PIUNA Research Program of the University of Navarra. Authors would like to thank EVENA (Estación de Viticultura y Enología de Navarra) for providing the samples used in this project. I.E., I.S. and S.G. would like to thank the local Government of Navarra and the Friends of the University of Navarra, Incorporated, for funding support. 